\title{
Detection of Horizontal Gene Transfers from Phylogenetic Comparisons
}

\author{
Victor Satler Pylro, ${ }^{1}$ Luciano de Souza Vespoli, ${ }^{2}$ \\ Gabriela Frois Duarte, ${ }^{3}$ and Karla Suemy Clemente Yotoko ${ }^{4}$ \\ ${ }^{1}$ Laboratório de Biodiversidade e Biotecnologia para o Meio Ambiente, Departamento de Microbiologia, \\ Universidade Federal de Viçosa, Avenida P.H. Rolfs, s/n, Viçosa, MG, Brazil \\ ${ }^{2}$ Laboratório de Biotecnologia, CCTA, Universidade Estadual do Norte Fluminense Darcy Ribeiro, Avenida Alberto Lamego, 2000, \\ Parque Califórnia, Campos dos Goytacazes, RJ, Brazil \\ ${ }^{3}$ Centro Universitário Newton Paiva, Escola de Engenharia e Arquitetura, Rua José Cláudio Rezende, 420, Estoril, \\ CEP 30494-230 Belo Horizonte, MG, Brazil \\ ${ }^{4}$ Laboratório de Bioinformática e Evolução, Universidade Federal de Viçosa, Avenida P.H. Rolfs, s/n, Viçosa, MG, Brazil
}

Correspondence should be addressed to Victor Satler Pylro, victor.pylro@ufv.br

Received 9 February 2012; Revised 22 March 2012; Accepted 23 March 2012

Academic Editor: Hiromi Nishida

Copyright (C) 2012 Victor Satler Pylro et al. This is an open access article distributed under the Creative Commons Attribution License, which permits unrestricted use, distribution, and reproduction in any medium, provided the original work is properly cited.

Bacterial phylogenies have become one of the most important challenges for microbial ecology. This field started in the mid-1970s with the aim of using the sequence of the small subunit ribosomal RNA (16S) tool to infer bacterial phylogenies. Phylogenetic hypotheses based on other sequences usually give conflicting topologies that reveal different evolutionary histories, which in some cases may be the result of horizontal gene transfer events. Currently, one of the major goals of molecular biology is to understand the role that horizontal gene transfer plays in species adaptation and evolution. In this work, we compared the phylogenetic tree based on $16 \mathrm{~S}$ with the tree based on $d s z \mathrm{C}$, a gene involved in the cleavage of carbon-sulfur bonds. Bacteria of several genera perform this survival task when living in environments lacking free mineral sulfur. The biochemical pathway of the desulphurization process was extensively studied due to its economic importance, since this step is expensive and indispensable in fuel production. Our results clearly show that horizontal gene transfer events could be detected using common phylogenetic methods with gene sequences obtained from public sequence databases.

\section{Introduction}

The discussion concerning bacteria phylogenies has become one of the most important aspects of microbial ecology. In the mid-1970s, Woese and his collaborators proposed and began assembling a significant database of sequence information based on small subunit ribosomal RNA (SSU rRNA $16 \mathrm{~S}$ ). The current universal tree is based on this [1-6], since it is easily sequenced $( \pm 1,500$ nucleotides) and widely available in sequence databases (Gen-Bank, EMBL) $[7,8]$. However, phylogenetic hypotheses based on several other genes result in conflicting topologies and reveal different evolutionary histories. In many cases, especially within bacteria, these may be the result of horizontal gene transfers (HGTs) [9, 10], which are regarded as a crucial mechanism of increasing genetic variability among bacteria [11-13]. Currently, one of the major goals of molecular biology is to understand the role that HGT plays in species adaptation and evolution $[10,14,15]$. The presence of HGT in bacteria has been reported for several years, suggesting that for some genes the tree of life becomes a net [16]. HGT is dominant among various groups of genes in prokaryotes such as antibiotic resistance, carbon source utilization, organic contaminant degradation, and freeze tolerance genes [12, 13]. However, there is some evidence of HGT in housekeeping genes such as those for replication, transcription, and translation as well $[10,17,18]$.

Sulphur is the third most abundant element in petroleum (after carbon and hydrogen), and its release contributes to air pollution by causing acid rain $[19,20]$. For this reason, 
sulphur regulations have continued to become more stringent and it is necessary to remove sulphur oxides from fossil fuels during the refining process. Most inorganic and simple organic sulphur can be removed by hydrodesulphurization, the technique currently used by most petroleum refineries, but, in petroleum, the majority of sulphur is found in dibenzothiophene (DBT) and its derivatives, which can only be removed through a specific biological mechanism called biodesulphurization [21]. Several studies have investigated the development of aerobic microbial desulphurisation pathways [22-24].

Some bacteria can desulphurize DBT to 2-hydroxybiphenyl (2-HBP) through the sulphur-specific degradation pathway (4S pathway) without destroying the hydrocarbon skeleton [22, 24-26]. In natural environments, the cleavage of carbon-sulfur bonds in molecules such as DBT liberates sulfur, making it available as a nutrient to support the growth of bacteria in environments poor in mineral sulfur [27]. These bacteria have been assigned to a number of genera including Rhodococcus [21, 28], Acinetobacter, and Pseudomonas [24]. Species of other bacteria genera, such as Brevibacterium sp. strain DO [29], strains identified as Arthrobacter spp. [30], and Gordonia sp. strain CYKS1 [31], are also able to use this pathway.

The pSOX plasmid [28], or $d s z$ genes [32, 33], responsible for the sulfur oxidation in DBT, have been cloned, sequenced, and studied, generating considerable knowledge of these pathway enzymes $[28,32,34]$. The $4 S$ pathway consists of three genes designated $d s z \mathrm{~A}, \mathrm{~B}$, and C. Studies have shown that the product of $d s z \mathrm{C}$ directly converts $\mathrm{DBT}$ to DBTO2 and the products of $d s z \mathrm{~A}$ and $d s z \mathrm{~B}$ act together to convert DBTO2 to 2-HBP. The operon $d s z$ occupies a $4 \mathrm{~kb}$ gene locus in a $120 \mathrm{~kb}$ linear plasmid in bacteria Rhodococcus erythropolis strain IGTS8 [28, 32, 35-37]. The plasmid nature of the $d s z$ genes increases the probability of successful transfers, and the availability of the $d s z \mathrm{C}$ sequences in GenBank allows the construction of phylogenetic hypothesis based on this gene, in order to compare it with the 16S.

In this work, we aim to demonstrate the utility of phylogenetic methods based on molecular data to help in studies of horizontal transfer of functional genes in bacteria.

\section{Materials and Methods}

2.1. Nucleotide Sequences. The nucleotide sequences used in this study were obtained from the National Center for Biotechnology Information-GenBank (http://www.ncbi .nlm.nih.gov). For analyses involving the $d s z \mathrm{C}$ gene, 18 sequences were selected (Table 1), representing all genera and/or species with $d s z \mathrm{C}$ sequences available in the database as of March 2012. We also searched for the other two genes of the operon, $d s z \mathrm{~A}$ and $d s z \mathrm{~B}$, but they are underrepresented in GenBank and phylogenetic trees could not be constructed based on these genes. For the $16 \mathrm{~S}$ gene, we chose 39 sequences, including at least two sequences of at least $1400 \mathrm{bp}$ from each genera and/or species in the $d s z \mathrm{C}$ tree (Table 2).
TABLE 1: Bacteria species names and NCBI accession number of $d s z \mathrm{C}$ sequences used.

\begin{tabular}{lc}
\hline Bacteria species & $\begin{array}{c}\text { NCBI accession } \\
\text { numbers }\end{array}$ \\
\hline Acidovorax delafieldii & DQ062154.1 \\
Agrobacterium tumefaciens & AY960127.1 \\
Bacillus subtilis & AB076745.1 \\
Mycobacterium sp. strain G3 & AB070603.1 \\
Brevibacillus brevis & DQ062161.1 \\
Gordonia alkanivorans strain 1B & AY678116.1 \\
Gordonia alkanivorans & AY714057.1 \\
Gordonia alkanivorans strain RIPI90A & EU364831.1 \\
Gordonia sp. strain CYKS2 & AY396519.1 \\
Mycobacterium goodii strain X7B & EU527978.1 \\
Rhodococcus erythropolis & AY714058.1 \\
Rhodococcus erythropolis & AY294404.1 \\
Rhodococcus sp. strain IGTS8 & L37363.1 \\
Rhodococcus sp. strain IIPS7 & DQ198086.1 \\
Rhodococcus sp. strain SDUZAWQ & AY789136.1 \\
Rhodococcus sp. strain XP & AY278323.1 \\
Synthetic construct dibenzothiophene & \\
monooxygenase (sequence from & EF570783.1 \\
Rhodococcus sp. LY822) & \\
\hline
\end{tabular}

2.2. Phylogenetic Analysis. Phylogenetic analyses were performed with four different methods: neighbour joining (NJ) using the program MEGA 5.0 [38]; maximum parsimony (MP) and maximum likelihood (ML) using the program PAUP* [39]; Bayesian inference (BA) using the program MrBayes [40]. For NJ, ML, and BA, we chose the best nucleotide substitution model using the programs Mega 5.0 [38], ModelTest [41], and MrModelTest [42]. The chosen models are shown in Table 3. We used the Tree Bisection and Reconnection heuristic search method to search for the MP and ML trees. The MP tree started with a random tree, while the ML tree started with an NJ tree. To infer the tree through the BA, we run two independent analyses with four chains each (one cold and three hot chains), started with four different random trees modified through 5,000,000 generations of MCMC. We checked the likelihood of the resulting topologies and burned-out $25 \%$ of the trees (to keep those within the area of the best likelihoods) to construct the consensus tree. The robustness of each node of the tree was obtained by the bootstrap test (MV, MP, and $\mathrm{NJ}$ ); the posterior probability was calculated by the frequency of each node in the consensus BA tree.

2.3. Phylogenetic Network Estimation of $d s z C$ Genes. Given the phylogenetic hypothesis for the $d s z \mathrm{C}$ gene, we constructed a network using the most related haplotypes with statistical-parsimony analyses [43]. The graphic network was constructed using TCS vers. 1.21 [44]. This method starts by calculating the overall limits of parsimony for the complete 
TABLE 2: Bacteria species names and NCBI accession number of $16 \mathrm{~S}$ sequences used.

\begin{tabular}{|c|c|}
\hline Bacteria species & $\begin{array}{c}\text { NCBI accession } \\
\text { number }\end{array}$ \\
\hline Acidovorax delafieldii strain 179 & EU730925.1 \\
\hline Acidovorax delafieldii strain NBGD35 & HQ003420.1 \\
\hline Agrobacterium tumefaciens strain NBGD13 & HQ003411.1 \\
\hline Agrobacterium tumefaciens strain SJ61 & GQ140318.1 \\
\hline Agrobacterium tumefaciens strain SJ22 & GQ140317.1 \\
\hline Bacillus subtilis strain DmB55 & HQ111354.1 \\
\hline Bacillus subtilis strain CCM7 & HQ108184.1 \\
\hline Bacillus subtilis strain ANctcri3 & HQ286641.1 \\
\hline Bacillus subtilis strain 13B & HQ335318.1 \\
\hline Brevibacillus brevis strain NBGD26 & HQ003422.1 \\
\hline Brevibacillus brevis strain $\mathrm{H} 2$ & HM449127.1 \\
\hline Brevibacillus brevis strain EIF87 & HM480358.1 \\
\hline Brevibacillus brevis strain Hot-1 & EU327889.1 \\
\hline Gordonia alkalivorans & Y18054.1 \\
\hline Gordonia alkanivorans strain DSM 44187 & AY995556.1 \\
\hline Gordonia alkanivorans strain TPR13 & EU373422.1 \\
\hline Gordonia alkanivorans strain HKI 0136 & NR_026488.1 \\
\hline Gordonia amicalis strain IEGM & NR_028735.1 \\
\hline Gordonia amicalis strain CC-MJ-2a & EU266484.1 \\
\hline Gordonia amicalis strain CC-MJ-15b & EU266486.1 \\
\hline Gordonia amicalis & AF101418.1 \\
\hline Mycobacterium avium strain M214 & GU142929.1 \\
\hline Mycobacterium avium complex strain 27497 & EF611344.1 \\
\hline Mycobacterium avium strain ATCC 19698 & EF521896.1 \\
\hline Mycobacterium avium strain ATCC 25291 & EF521895.1 \\
\hline Mycobacterium avium strain IWGMT49 & EF521892.1 \\
\hline Mycobacterium goodii & Y12872.1 \\
\hline Mycobacterium goodii strain M069 & NR_029341.1 \\
\hline Mycobacterium goodii strain X7B & AF513815.1 \\
\hline Rhodococcus erythropolis strain ZJB-0910 & GU726138.1 \\
\hline Rhodococcus erythropolis strain MJ2 & GU991529.1 \\
\hline Rhodococcus erythropolis strain $13648 \mathrm{E}$ & EU741153.1 \\
\hline Rhodococcus erythropolis strain e1 & EU434599.1 \\
\hline Rhodococcus sp. NKCM 2512 & AB591806.1 \\
\hline Rhodococcus sp. BY44 & FR690460.1 \\
\hline Rhodococcus sp. ITP08 & FR667175.1 \\
\hline Rhodococcus sp. SH15 & HM590053.1 \\
\hline Rhodococcus equi strain ATCC 6939 & FJ468344.1 \\
\hline Rhodococcus erythropolis strain XP & DQ074453.1 \\
\hline
\end{tabular}

data set using a statistic from neutral coalescent theory $[45,46]$. Although this method has been used extensively with restriction site and nucleotide sequence data to estimate population level genealogies when divergences are low (intraspecific data) $[46,47]$, it also proved to be reliable at higher divergences, outperforming parsimony and parsimony with bootstrapping [48].

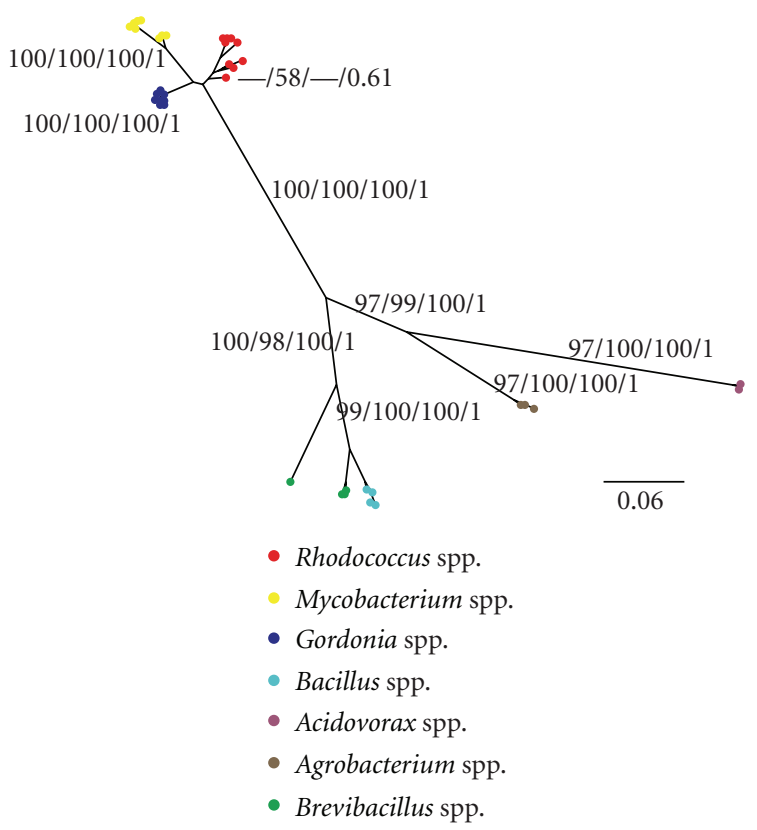

Figure 1: Tree obtained by BA analysis from sequences of the $16 \mathrm{~S}$ gene. The values on the branches represent bootstrap values of NJ, $\mathrm{MV}$, and MP and posterior probability of the BA analysis.

\section{Results and Discussion}

The BA hypotheses for the 16S gene are shown in Figure 1, which presents the expected pattern of species grouped within their respective genera. The different phylogenetic methods resulted in very similar tree topologies (data not shown) and robust bootstrap values for NJ, ML, MP, and BA posterior probability of the branches. The only exception was the branch containing representatives from the Rhodococcus spp. (in red), which showed low bootstrap value in MP $(58 \%)$, low posterior probability value in BA (0.61), and bootstrap values for $\mathrm{NJ}$ and $\mathrm{ML}<50 \%$. Although the convergence of results using different phylogenetic methods has been considered good evidence that the correct phylogeny was obtained [49], total genome phylogenies show that different phylogenetic methods can provide incongruent phylogenies [50, 51]. However, the comparison of $16 \mathrm{~S}$ sequences is still considered a powerful and accepted tool for deducing phylogenetic and evolutionary relationships among bacteria and is routinely used [4, 52-54]. In fact, most of bacteria systematics is based on the topologies generated by this gene [3].

Figure 2, on the other hand, did not group the species by genera. Instead, this figure presents only three branches: the first includes Mycobacterium sp. (strain G3-AB070603.1) and Bacillus subtilis (AB076745.1) sequences; the second groups two sequences of Gordonia alkanivorans (strain $1 \mathrm{~B}-$ AY678116.1 and strain RIPI90A-EU364831.1); the third clusters all remaining sequences belonging to all genera included in this work except for Bacillus. It is expected that molecular phylogenies based on single genes lead to apparently conflicting results with alternative branches that present low bootstrap (or posterior probability) values [50]. 
TABLE 3: Software, nucleotide substitution models and criteria used for phylogenetic analysis of $16 \mathrm{~S}$ and $d s z \mathrm{C}$ genes in each tested method.

\begin{tabular}{lcccc}
\hline Method & Gene & $\begin{array}{c}\text { Nucleotide } \\
\text { substitution model }\end{array}$ & $\begin{array}{c}\text { Gamma } \\
\text { distribution }\end{array}$ & $\begin{array}{c}\text { Invariable sites } \\
\text { proportion }\end{array}$ \\
\hline NJ & $d s z \mathrm{C}$ & Tamura-Nei & 0.71 & - \\
& $16 \mathrm{~S}$ & Tamura-Nei & 0.69 & - \\
ML & $d s z \mathrm{C}$ & GTR+G & 0.8291 & 0.3667 \\
& $16 \mathrm{~S}$ & GTR+G+I & 0.8125 & - \\
BA & $d s z \mathrm{C}$ & GTR+G & 0.8291 & 0.3667 \\
\hline
\end{tabular}

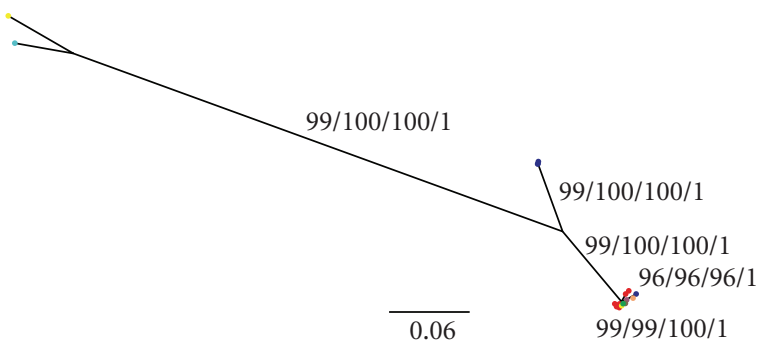

- Rhodococcus sp.

- Mycobacterium sp.

- Gordonia sp.

- Bacillus sp.

- Synthetic construct dibenzothiophene monooxygenase

- Acidovorax sp.

- Agrobacterium sp.

- Brevibacillus sp.

Figure 2: Tree obtained by BA analysis from sequences of the $d s z \mathrm{C}$ gene. The values on the branches represent bootstrap values of $\mathrm{NJ}$, $\mathrm{MV}$, and MP and posterior probability of the BA analysis.

However, the conflicting topologies shown in Figures 1 and 2 present high bootstrap and posterior probability values in alternative branches, strongly suggesting that the $d s z C$ was indeed subjected to horizontal transfer events among these bacteria.

The phylogenetic network estimation (Figure 3 ) of the $d s z \mathrm{C}$ haplotypes of the most specious cluster shown in Figure 2 emphasizes the fact that Acidovorax delafieldii (Seq 1), Agrobacterium tumefaciens (Seq 2), Brevibacillus brevis (Seq 3), and Rhodococcus sp. (Seq 11) present identical sequences, which were grouped together as a square within Figure 3, while other haplotypes are displayed as ovals connected to the square by lines with black circles to indicate the maximum number of steps between each pair of haplotypes.

The results presented here, based solely on GenBank data, provide strong evidence that the $d s z \mathrm{C}$ gene was horizontally transferred among different evolutionary lineages of bacteria. This evidence is reinforced by the fact that the $d c z C$ gene is generally found in conjugative plasmids, in the vicinity of insertion sequences, transcribed in the same direction and under the control of a single promoter $[35,37$,
$55,56]$. Furthermore, another evidence of $d s z \mathrm{C}$ horizontal transfer is the significant difference of the $\mathrm{C}+\mathrm{G}$ content of this gene with the $\mathrm{C}+\mathrm{G}$ content of the entire chromosome of some species studied here (data not shown).

Our results reinforce the importance of public sequence repositories (such as GenBank), which result from a successful policy of requiring the inclusion of gene sequences in public databases in order to publish any research article containing sequence analyses $[57,58]$. In addition to the DNA sequence of each entry, GenBank and other public databases include associated metadata, which provide relevant information about the organism whose sequence is available, generally by linking to the articles with the respective sequence [58]. However, the public databases also contain several molecular sequences submitted by researchers who have not published their results. In these cases, there is neither citation information nor any relevant data about the organisms from which the sequences were made, which in most cases makes the sequences useless for in silico works, since diverse knowledge about a given molecular sequence provides an essential first step in developing research hypotheses.

It is easy to generate new sequences and add them to the GenBank database, which contains about 150 million gene sequences as of February 2012. However, GenBank, along with its INSDC (International Nucleotide Sequence Database Collaboration) partners (EMBL \& DDBJ), should be treated not only as archival stores of molecular sequence data (a task at which it has been very successful) but also as a starting point for future studies. In this context, it would be helpful if the process of submitting sequences required a minimum of information about the organism from which the sequences were made, as well as the details of the gene sequenced, in order to substantiate future research.

In this sense, our study could be improved if flanking DNA sequences of functional genes such as $d s z \mathrm{C}$ were available in the databases, since we could then evaluate if one set of $d s z$ genes is flanked by a particular insertion sequence while another cluster is not.

Although laboratory data that demonstrate the transfer by conjugation of plasmids containing $d s z$ genes or transposition of these genes are scarce, their distribution in bacterial cultures strongly supports the hypothesis that these genes are commonly subject to horizontal transfer in nature as evidenced in the present work. For this reason, we conclude that phylogenetic tools can be useful for inferring horizontal 


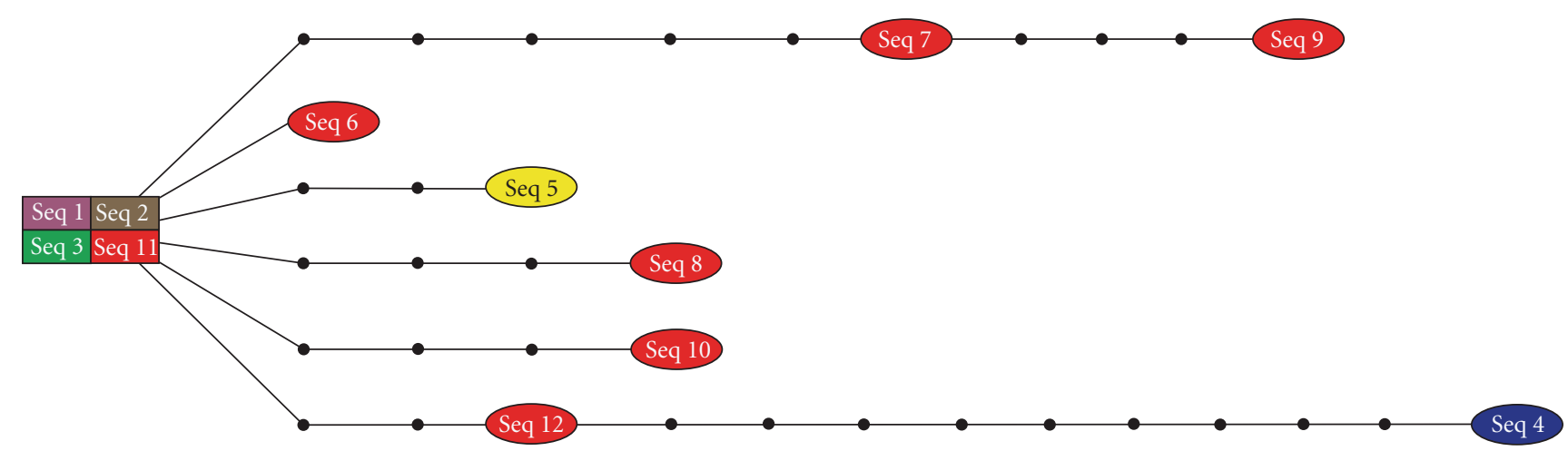

Figure 3: Phylogenetic network estimation of $d s z \mathrm{C}$ genes that remained grouped after phylogenetic analyses. Seq 1: Acidovorax delafieldii (DQ062154.1); Seq 2: Agrobacterium tumefaciens (AY960127.1); Seq 3: Brevibacillus brevis (DQ062161.1); Seq 4: Gordonia alkanivorans (AY714057.1); Seq 5: Mycobacterium goodii (EU527978.1); Seq 6: Rhodococcus erythropolis (AY714058.1); Seq 7: Rhodococcus erythropolis (AY294404.1); Seq 8: Rhodococcus sp. (L37363.1); Seq 9: Rhodococcus sp. (DQ198086.1); Seq 10: Rhodococcus sp. (AY789136.1); Seq 11: Rhodococcus sp. (AY278323.1); Seq 12: Synthetic construct dibenzothiophene monooxygenase (EF570783.1).

transfer events of functional genes such as $d s z \mathrm{C}$. Phylogenetic comparisons with other genes traditionally used for this purpose, such as $16 \mathrm{~S}$, can provide good information about evolution and functional gene distribution.

Lateral gene transfer events provide a venue for bacterial diversification by rearranging existing capabilities. Because bacterial genomes can maintain only a finite amount of information, they are sampling rather than accumulating sequences, counterbalancing gene acquisition with gene loss. As a result, lateral gene transfer can redefine the ecological niche of a microorganism, in effect promoting bacterial speciation [58]. Although a potential result of interspecific recombination is the uncertainty of species boundaries, the increased mixing of genes and the observed phylogenetic inconsistencies show the history of a gene-transfer-mediated diversification of microorganisms.

\section{Acknowledgments}

The authors would like to thank M.S. Marcos M. D. Carneiro for help in reviewing the English of this work, M.S. Gilberto de O. Mendes for his help in editing the figures, M.S. Mateus Ferreira Santana for his help in phylogenetic network analyses, and FAPEMIG, CNPq, and CAPES for financial support. This paper is dedicated in memoriam of Aurea C. S. Pylro.

\section{References}

[1] C. R. Woese and G. E. Fox, "Phylogenetic structure of the prokaryotic domain: the primary kingdoms," Proceedings of the National Academy of Sciences of the United States of America, vol. 74, no. 11, pp. 5088-5090, 1977.

[2] C. R. Woese, "Bacterial evolution," Microbiological Reviews, vol. 51, no. 2, pp. 221-271, 1987.

[3] C. R. Woese, O. Kandler, and M. L. Wheelis, "Towards a natural system of organisms: proposal for the domains Archaea, Bacteria, and Eucarya," Proceedings of the National Academy of Sciences of the United States of America, vol. 87, no. 12, pp. 4576-4579, 1990.
[4] S. Winker and C. R. Woese, "A definition of the domains Archaea, Bacteria and Eucarya in terms of small subunit ribosomal RNA characteristics," Systematic and Applied Microbiology, vol. 14, no. 4, pp. 305-310, 1991.

[5] G. J. Olsen, N. Larsen, and C. R. Woese, "The ribosomal RNA database project," Nucleic Acids Research, vol. 19, pp. 20172021, 1991.

[6] B. L. Maidak, G. J. Olsen, N. Larsen, R. Overbeek, M. J. McCaughey, and C. R. Woese, "The RDP (Ribosomal Database Project)," Nucleic Acids Research, vol. 25, no. 1, pp. 109110, 1997.

[7] H. L. Coutinho, V. M. De Oliveira, G. P. Manfio, and A. S. Rosado, "Evaluating the microbial diversity of soil samples: methodological innovations.", Anais da Academia Brasileira de Ciências, vol. 71, no. 3, pp. 491-503, 1999.

[8] D. A. Stahl, "Molecular approaches for the measurement of density, diversity and phylogeny," in Manual of Environmental Microbiology, C. J. Hurst, G. R. Knudsen, M. J. McInerney, L. D. Stetzenbach, and M. V. Walter, Eds., pp. 102-114, ASM Press, Washington, DC, USA, 1997.

[9] W. Martin, "Mosaic bacterial chromosomes: a challenge en route to a tree of genomes," BioEssays, vol. 21, no. 2, pp. 99104, 1999.

[10] W. F. Doolittle, "Phylogenetic classification and the universal tree," Science, vol. 284, no. 5423, pp. 2124-2128, 1999.

[11] S. Paytubi, J. García, and A. Juárez, "Bacterial Hha-like proteins facilitate incorporation of horizontally transferred DNA," Central European Journal of Biology, vol. 6, no. 6, pp. 879-886, 2011.

[12] R. E. Collins and J. W. Deming, "Abundant dissolved genetic material in Arctic sea ice Part II: viral dynamics during autumn freeze-up," Polar Biology, vol. 34, no. 12, pp. 18191830, 2011.

[13] R. C. Baños, A. Vivero, S. Aznar et al., "Differential regulation of horizontally acquired and core genome genes by the bacterial modulator H-NS," PLoS Genetics, vol. 5, no. 6, Article ID e1000513, 2009.

[14] E. V. Koonin, "Horizontal gene transfer: The path to maturity," Molecular Microbiology, vol. 50, no. 3, pp. 725-727, 2003.

[15] A. Boc and V. Makarenkov, "Towards an accurate identification of mosaic genes and partial horizontal gene transfers," Nucleic Acids Research, vol. 39, no. 21, article e144, 2011. 
[16] E. Hilario and J. P. Gogarten, "Horizontal transfer of ATPase genes-the tree of life becomes a net of life," BioSystems, vol. 31, no. 2-3, pp. 111-119, 1993.

[17] J. N. Bautista-Zapanta, H. H. Arafat, K. Tanaka, H. Sawada, and K. Suzuki, "Variation of 16S-23S internally transcribed spacer sequence and intervening sequence in rDNA among the three major Agrobacterium species," Microbiological Research, vol. 164, no. 6, pp. 604-612, 2009.

[18] T. Asai, D. Zaporojets, C. Squires, and C. L. Squires, "An Escherichia coli strain with all chromosomal rRNA operons inactivated: complete exchange of rRNA genes between bacteria," Proceedings of the National Academy of Sciences of the United States of America, vol. 96, no. 5, pp. 1971-1976, 1999.

[19] Y. Tanaka, T. Matsui, J. Konishi, K. Maruhashi, and R. Kurane, "Biodesulfurization of benzothiophene and dibenzothiophene by a newly isolated Rhodococcus strain," Applied Microbiology and Biotechnology, vol. 59, no. 2-3, pp. 325-328, 2002.

[20] T. Ohshiro and Y. Izumi, "Microbial desulfurization of organic sulfur compounds in petroleum," Bioscience, Biotechnology, and Biochemistry, vol. 63, no. 1, pp. 1-9, 1999.

[21] F. Davoodi-Dehaghani, M. Vosoughi, and A. A. Ziaee, "Biodesulfurization of dibenzothiophene by a newly isolated Rhodococcus erythropolis strain," Bioresource Technology, vol. 101, no. 3, pp. 1102-1105, 2010.

[22] J. H. Chang, Y. K. Chang, K. S. Cho, and H. N. Chang, "Desulfurization of model and diesel oils by resting cells of Gordona sp.," Biotechnology Letters, vol. 22, no. 3, pp. 193-196, 2000.

[23] G. F. Duarte, A. S. Rosado, L. Seldin, W. De Araujo, and J. D. Van Elsas, "Analysis of Bacterial Community Structure in Sulfurous-Oil-Containing Soils and Detection of Species Carrying Dibenzothiophene Desulfurization (dsz) Genes," Applied and Environmental Microbiology, vol. 67, no. 3, pp. 1052-1062, 2001.

[24] D. Boniek, D. Figueiredo, V. S. Pylro, and G. F. Duarte, "Characterization of bacterial strains capable of desulphurisation in soil and sediment samples from Antarctica," Extremophiles, vol. 14 , no. 5, pp. 475-481, 2010.

[25] E. S. Olson, D. C. Stanley, and J. R. Gallagher, "Characterization of intermediates in the microbial desulfurization of dibenzothiophene," Energy \& Fuels, vol. 7, no. 1, pp. 159-164, 1993.

[26] S. Nekodzuka, T. Nakajima-Kambe, N. Nomura, J. Lu, and T. Nakahara, "Specific desulfurization of dibenzothiophene by Mycobacterium sp. strain G3," Biocatalysis and Biotransformation, vol. 15, no. 1, pp. 17-27, 1997.

[27] J. J. Kilbane Ii and S. Le Borgne, "Petroleum biorefining: the selective removal of sulfur, nitrogen, and metals," in Studies in Surface Science and Catalysis, V.-D. Rafael and Q.-R. Rodolfo, Eds., Chapter 2, pp. 29-65, Elsevier, 2004.

[28] S. A. Denome, C. Oldfield, L. J. Nash, and K. D. Young, "Characterization of the desulfurization genes from Rhodococcus sp. strain IGTS8," Journal of Bacteriology, vol. 176, no. 21, pp. 6707-6716, 1994.

[29] M. Van Afferden, S. Schacht, J. Klein, and H. G. Truper, "Degradation of dibenzothiophene by Brevibacterium sp.DO," Archives of Microbiology, vol. 153, no. 4, pp. 324-328, 1990.

[30] M. K. Lee, J. D. Senius, and M. J. Grossman, "Sulfur-specific microbial desulfurization of sterically hindered analogs of dibenzothiophene," Applied and Environmental Microbiology, vol. 61, no. 12, pp. 4362-4366, 1995.
[31] S. K. Rhee, J. H. Chang, Y. K. Chang, and H. N. Chang, "Desulfurization of dibenzothiophene and diesel oils by a newly isolated Gordona strain, CYKS1," Applied and Environmental Microbiology, vol. 64, no. 6, pp. 2327-2331, 1998.

[32] C. S. Piddington, B. R. Kovacevich, and J. Rambosek, "Sequence and molecular characterization of a DNA region encoding the dibenzothiophene desulfurization operon of Rhodococcus sp. strain IGTS8," Applied and Environmental Microbiology, vol. 61, no. 2, pp. 468-475, 1995.

[33] M. Z. Li, C. H. Squires, D. J. Monticello, and J. D. Childs, "Genetic analysis of the dsz promoter and associated regulatory regions of Rhodococcus erythropolis IGTS8," Journal of Bacteriology, vol. 178, no. 22, pp. 6409-6418, 1996.

[34] S. A. Denome, E. S. Olson, and K. D. Young, "Identification and cloning of genes involved in specific desulfurization of dibenzothiophene by Rhodococcus sp. strain IGTS8," Applied and Environmental Microbiology, vol. 59, no. 9, pp. 2837-2843, 1993.

[35] C. Oldfield, O. Pogrebinsky, J. Simmonds, E. S. Olson, and C. F. Kulpa, "Elucidation of the metabolic pathway for dibenzothiophene desulphurization by Rhodococcus sp. strain IGTS8 (ATCC 53968)," Microbiology, vol. 143, no. 9, pp. 29612973, 1997.

[36] J. J. Kilbane, "Desulfurization of coal: the microbial solution," Trends in Biotechnology, vol. 7, no. 4, pp. 97-101, 1989.

[37] C. Denis-Larose, D. Labbé, H. Bergeron et al., "Conservation of plasmid-encoded dibenzothiophene desulfurization genes in several rhodococci," Applied and Environmental Microbiology, vol. 63, no. 7, pp. 2915-2919, 1997.

[38] K. Tamura et al., "MEGA5: molecular evolutionary genetics analysis using maximum likelihood, evolutionary distance, and maximum parsimony methods," Molecular Biology and Evolution, vol. 28, no. 10, pp. 2731-2739, 2011.

[39] D. L. Swofford, PAUP*. Phylogenetic Analysis Using Parsimony ( ${ }^{*}$ and Other Methods), Version 4, Sinauer Associates, Sunderland, Mass, USA, 2002.

[40] J. P. Huelsenbeck and F. Ronquist, "MRBAYES: Bayesian inference of phylogenetic trees," Bioinformatics, vol. 17, no. 8, pp. 754-755, 2001.

[41] D. Posada and K. A. Crandall, "MODELTEST: testing the model of DNA substitution," Bioinformatics, vol. 14, no. 9, pp. 817-818, 1998.

[42] J. A. A. Nylander, "MrModeltest v2. Program distributed by the auhor," Evolutionary Biology Centre, Uppsala University, Sweden, 2004.

[43] A. R. Templeton, K. A. Crandall, and C. F. Sing, "A cladistic analysis of phenotypic associations with haplotypes inferred from restriction endonuclease mapping and DNA sequence data. III. Cladogram estimation," Genetics, vol. 132, no. 2, pp. 619-633, 1992.

[44] M. Clement, D. Posada, and K. A. Crandall, “TCS: a computer program to estimate gene genealogies," Molecular Ecology, vol. 9, no. 10, pp. 1657-1659, 2000.

[45] R. R. Hudson, "How often are polymorphic restriction sites due to a single mutation?" Theoretical Population Biology, vol. 36, no. 1, pp. 23-33, 1989.

[46] J. Gómez-Zurita, E. Petitpierre, and C. Juan, "Nested cladistic analysis, phylogeography and speciation in the Timarcha goettingensis complex (Coleoptera, Chrysomelidae)," Molecular Ecology, vol. 9, no. 5, pp. 557-570, 2000.

[47] C. Vilà, I. R. Amorim, J. A. Leonard et al., "Mitochondrial DNA phylogeography and population history of the grey wolf Canis lupus," Molecular Ecology, vol. 8, no. 12, pp. 2089-2103, 1999. 
[48] K. A. Crandall, "Intraspecific cladogram estimation: accuracy at higher levels of divergence," Systematic Biology, vol. 43, no. 2, pp. 222-235, 1994.

[49] A. Rokas, B. I. Williams, N. King, and S. B. Carroll, "Genomescale approaches to resolving incongruence in molecular phylogenies," Nature, vol. 425, no. 6960, pp. 798-804, 2003.

[50] O. Jeffroy, H. Brinkmann, F. Delsuc, and H. Philippe, "Phylogenomics: the beginning of incongruence?" Trends in Genetics, vol. 22, no. 4, pp. 225-231, 2006.

[51] K. S. C. Yotoko and S. L. Bonatto, "A phylogenomic appraisal of the evolutionary relationship of Mycoplasmas," Genetics and Molecular Biology, vol. 30, no. 1, pp. 270-276, 2007.

[52] W. G. Weisburg, S. M. Barns, D. A. Pelletier, and D. J. Lane, "16S ribosomal DNA amplification for phylogenetic study," Journal of Bacteriology, vol. 173, no. 2, pp. 697-703, 1991.

[53] S. M. Hinsa-Leasure, L. Bhavaraju, J. L. M. Rodrigues, C. Bakermans, D. A. Gilichinsky, and J. M. Tiedje, "Characterization of a bacterial community from a Northeast Siberian seacoast permafrost sample," FEMS Microbiology Ecology, vol. 74, no. 1, pp. 103-113, 2010.

[54] D. Davolos and B. Pietrangeli, "Phylogenetic analysis on the arsenic-resistant bacteria isolated from three different freshwater environments," Chemistry and Ecology, vol. 27, no. 1, pp. 79-87, 2011.

[55] K. D. Young, "Identification and activity of two insertion sequence elements in Rhodococcus sp. strain IGTS8," Gene, vol. 161, no. 1, pp. 33-38, 1995.

[56] P. A. Williams, "Catabolic plasmids: fast-track bacterial evolution to combat pollution," Microbiology Today, vol. 31, pp. 168-171, 2004.

[57] D. A. Benson, I. Karsch-Mizrachi, D. J. Lipman, J. Ostell, and E. W. Sayers, "GenBank," Nucleic Acids Research, vol. 37, no. 1, pp. D26-D31, 2009.

[58] H. Miller, C. N. Norton, and I. N. Sarkar, "GenBank and PubMed: how connected are they?" BMC Research Notes, vol. 2, article no. 101, 2009. 

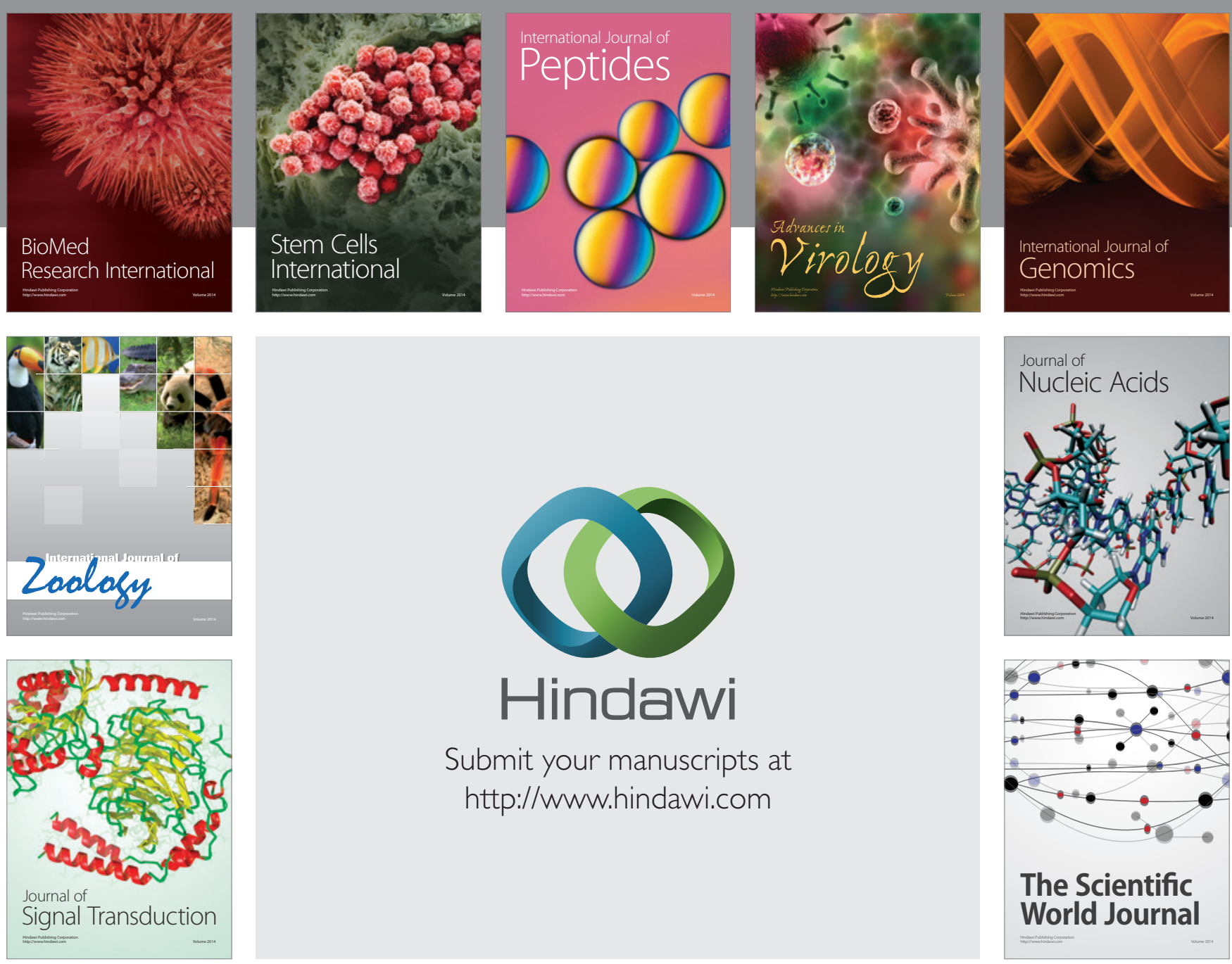

Submit your manuscripts at

http://www.hindawi.com
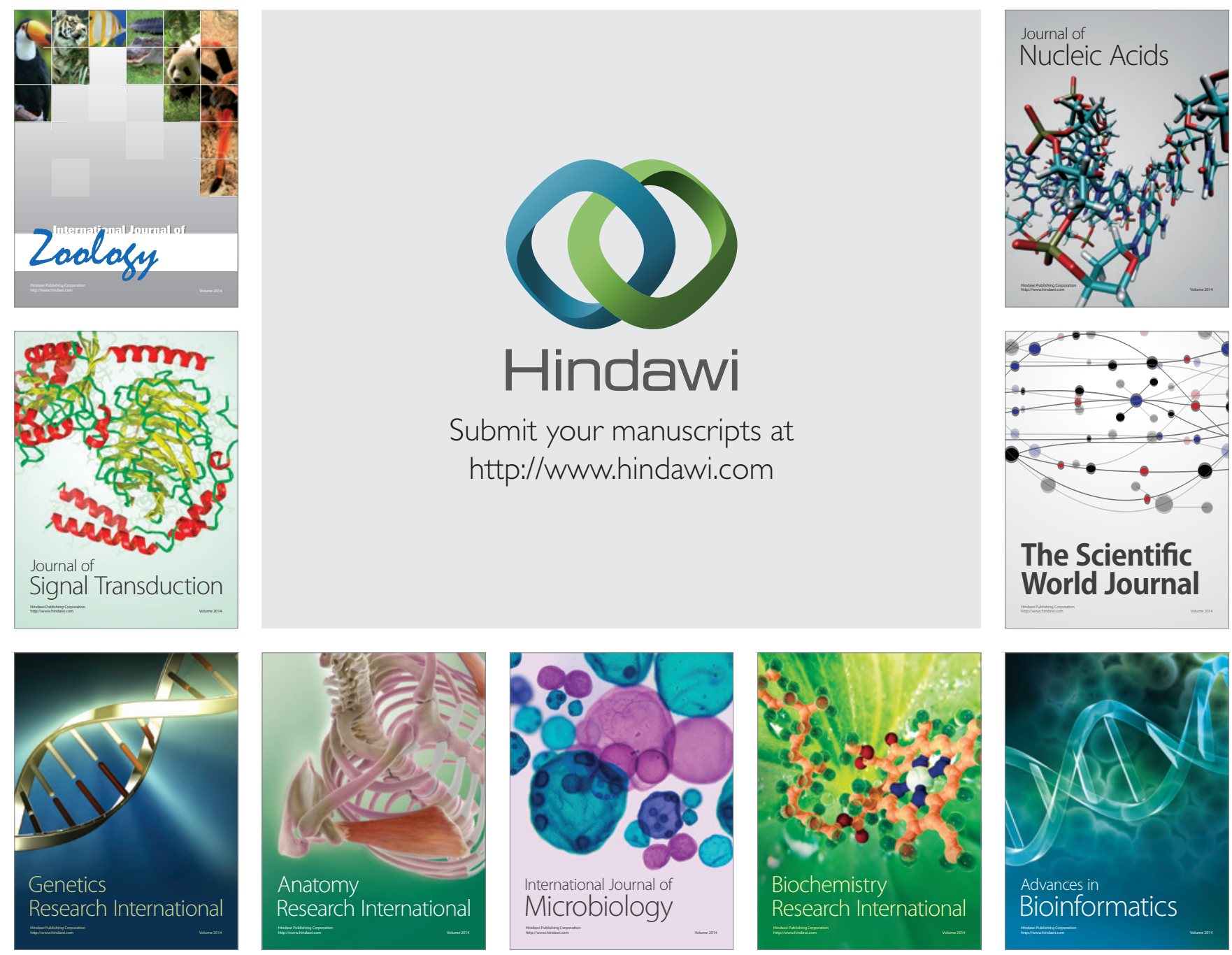

The Scientific World Journal
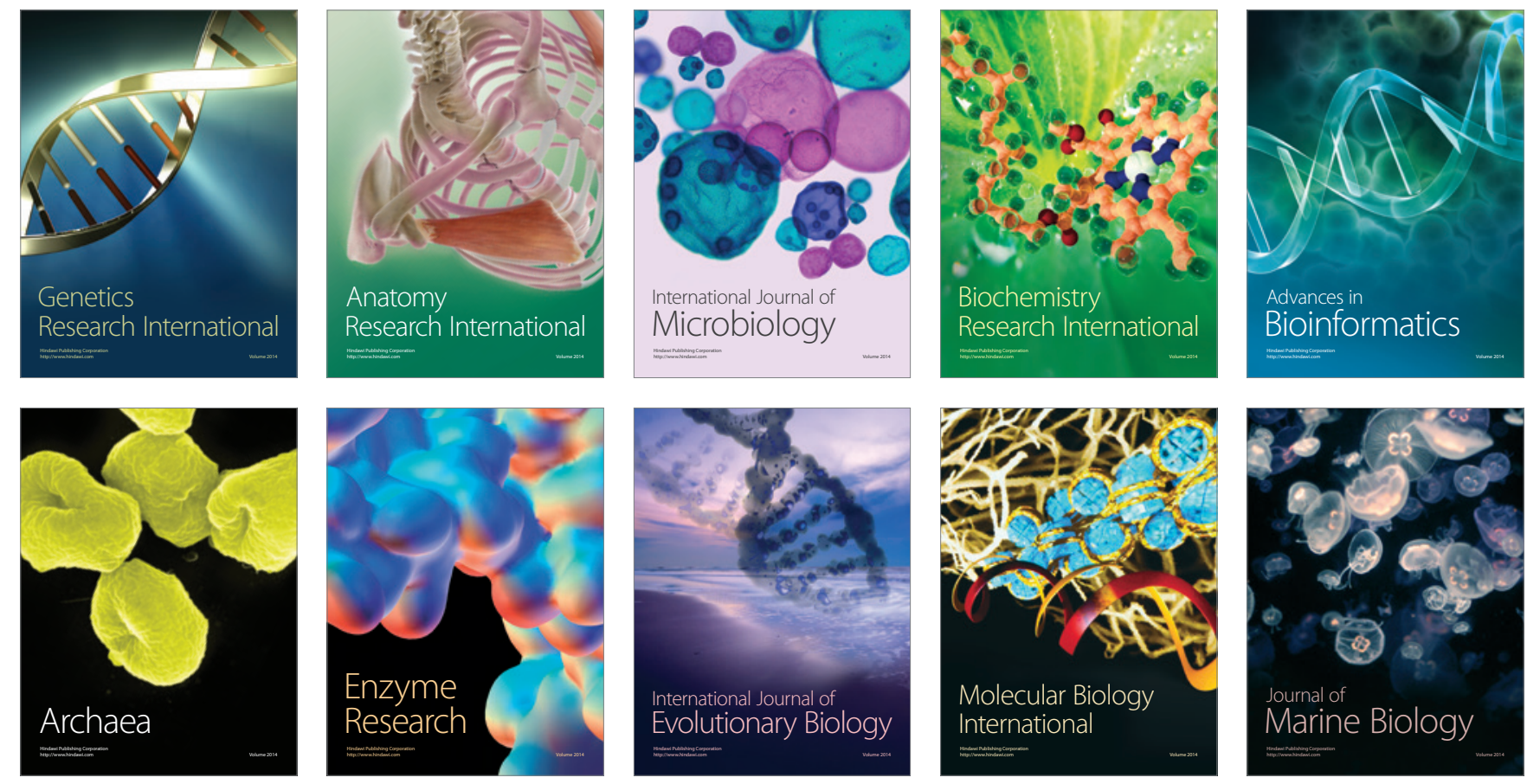